\title{
Examining the Relationship Between Children's ADHD Symptomatology and Inadequate Parenting: The Role of Household Chaos
}

\author{
Andrea Wirth ${ }^{1,2}$, Tilman Reinelt ${ }^{2,3}$, Caterina Gawrilow ${ }^{2,4,5}$, \\ Christina Schwenck ${ }^{6,7}$, Christine M. Freitag ${ }^{7}$, and Wolfgang A. Rauch ${ }^{2,8}$
}

\begin{abstract}
Objective: This study examines the interrelations of parenting practices, emotional climate, and household chaos in families with children with and without ADHD. In particular, indirect pathways from children's ADHD symptomatology to inadequate parenting and negative emotional climate via household chaos were investigated. Method: Parenting, emotional climate, and household chaos were assessed using questionnaires and a speech sample of parents of 31 children with and 53 without ADHD, aged 7 to 13 years. Results: Group differences were found for certain parenting dimensions, the parent-child relationship, critical comments, and household chaos. While we found significant indirect effects between children's ADHD and certain parenting dimensions through household chaos, no effects were found for any aspect of emotional climate. Conclusion: Children's ADHD symptoms translate into inadequate parenting through household chaos, which underlines the need for interventions to improve household organization skills in parents of children with ADHD. (J. of Att. Dis. 2019; 23(5) 45I-462)
\end{abstract}

\section{Keywords}

ADHD, parenting, expressed emotion, emotional climate, household chaos

Children with ADHD suffer from three symptom clusters: inattention, hyperactivity, and impulsivity. Thus, they are often inattentive in tasks or play activities, frequently lose things necessary for tasks or activities such as toys or school assignments, run about or climb excessively in situations in which it is inappropriate, and have difficulties awaiting their turn (Dilling, 2008). These core symptoms lead to impairments in social and academic functioning with often occurring problems in relationships with peers or within the family (Harpin, 2005).

Although the etiology of the core symptomatology of ADHD is known to be predominantly biological, in families with children with ADHD various aspects of the family environment have been related to academic performance, comorbidities, and social problems (Deault, 2010; Johnston $\&$ Mash, 2001). In general, several aspects need to be differentiated within the family environment of a child. First, parents behave toward their children in different ways that can be characterized by the amount of responsiveness, sensitivity, warmth, support, and acceptance as well as by discipline, monitoring, and autonomy granting (Kiff, Lengua, \& Zalewski, 2011; Maccoby, 2000). These mostly unidirectional parenting behaviors are directed from the parent toward the child to respond to requested or unrequested behavior shown by the child. Second, there are reciprocal and mutual habits, behaviors, and attitudes of parent-child dyads, such as (a) the emotional climate in a family which is characterized by the attitudes and feelings of family members toward each other (Vaughn \& Leff, 1976), or (b) the amount of household chaos, which describes a family environment that is noisy, crowded, and low in regularity and routines (Wachs \& Evans, 2010). Thus, emotional climate and household chaos do not pertain to parents exclusively,

\footnotetext{
'Goethe University Frankfurt, Germany

${ }^{2}$ Center for Individual Development and Adaptive Education of Children at Risk, Frankfurt, Germany

${ }^{3}$ University of Bremen, Germany

${ }^{4}$ German Institute for International Educational Research (DIPF), Frankfurt, Germany

${ }^{5}$ Eberhard Karls University Tübingen, Germany

${ }^{6}$ University of Kiel, Germany

${ }^{7}$ Department of Child and Adolescent Psychiatry, Psychosomatics and Psychotherapy, University Hospital Frankfurt, Goethe-University Frankfurt, Germany

${ }^{8}$ Heidelberg University, Germany

Corresponding Author:

Andrea Wirth, Department of Psychology, Goethe University Frankfurt, Theodor-W.-Adorno-Platz 6, 60629 Frankfurt, Germany.

Email: wirth@psych.uni-frankfurt.de
} 
but to the family system. In the following sections, we describe these different aspects and emphasize their association to the specificity of families with children with ADHD.

A lack of sensitivity and warmth as well as high hostility and strong punitive behavior, often described as inadequate parenting behavior, are associated with the development of externalizing disorders (Olson, Bates, Sandy, \& Lanthier, 2000). Parents of children with ADHD often display less positive as well as less consistent parenting, lower involvement, poorer communication skills, more harsh parenting, and more frequent use of physical discipline (Deault, 2010; Ellis \& Nigg, 2009; Lange et al., 2005). In general, their parenting behavior is characterized by more commanding and directive behavior, more disapproval, and fewer appreciations of the child's compliant behaviors (Johnston, 1996; Tripp, Schaughency, Langlands, \& Mouat, 2007). Thus, inadequate parenting is an essential risk factor for the course and the symptom severity of ADHD, such as for instance the development of externalizing and internalizing comorbidities or functional impairments in academic and social contexts (Deault, 2010). In the same vein, early positive parenting (i.e., authoritative parenting) can serve as a protective factor for the development of children with ADHD (Chronis et al., 2007; Latimer et al., 2003).

Another relevant aspect in a child's environment that is not directly related to parenting behavior, but to the interaction within a family (Peris \& Baker, 2000; Peris \& Miklowitz, 2015), is the emotional climate within a family, as for instance the parent-child relationship. In distinction from parenting behavior, which describes the way parents act toward their children to induce a certain behavior, the emotional climate is characterized by the attitudes and feelings of family members toward each other and therefore considers the emotional aspects within the parent-child relationship. A negative emotional climate as characterized by parental criticism, hostility, and a lack of warmth is strongly related to child behavioral problems (Baker, Heller, \& Henker, 2000; Peris \& Miklowitz, 2015) and predictive of child behavior problems later in school (Baker et al., 2000; Peris \& Baker, 2000). Attitudes and expressions of criticism, hostility, and a lack of warmth have been defined as an emotional climate of high expressed emotion (EE), which is often measured by speech samples. Starting with families of patients suffering from schizophrenia, EE and its role in the relation to psychiatric disorders have been studied since the 1960s (Brown \& Rutter, 1966), showing that the likelihood of relapse or an increase in the patient's symptoms was increased when the relatives showed high EE (Butzlaff \& Hooley, 1998). Regarding the development of psychopathology during childhood, high parental EE has been shown to predict treatment response and clinical course for obsessive-compulsive disorders and mood disorders (Asarnow, Goldstein, Tompson, \& Guthrie, 1993; Przeworski et al., 2012). Also, ADHD appears to be associated with high parental EE, as parents of children with ADHD report more negative statements, fewer positive comments, describe the mother-child relationship more negative and tensed, and express less warmth than mothers of typically developed children (Cartwright et al., 2011; Daley, Sonuga-Barke, \& Thompson, 2003; Peris \& Miklowitz, 2015; Sonuga-Barke et al., 2013). In addition, high EE measured in families with preschool children has been shown to be a predictor for later ADHD symptoms in middle childhood (Keown, 2012). Thus, in families with children with ADHD the emotional climate is often more negative as compared with families with typically developing children (Daley et al., 2003). An open question is whether parental EE is determined by individual variations of child symptoms (e.g., comorbid conduct problems), or by more general characteristics of the family (e.g., parental psychopathology; Cartwright et al., 2011; Sonuga-Barke et al., 2013). Investigating the relation between developmental trajectories of ADHD and parental EE longitudinally, parents of children with ADHD tended to criticize their children more and even more stable over time compared with parents of typically developing peers, even after controlling for comorbid disorders (Musser, Karalunas, Dieckmann, Peris, \& Nigg, 2016). In families that expressed stable high criticism to their child with ADHD, the decline in symptoms that is often shown in transition to adolescence did not occur, which outlines the importance to further examine parental EE in the context of ADHD (Musser et al., 2016). Hence, similar to parenting the EE components of high parental warmth, a positive relationship, and low criticism can serve as protective factors against children's behavior problems, too (Benard, 1991; Scaramella, Conger, \& Simons, 1999).

Another factor that affects a child's environment is household chaos, which is defined by a home environment that is high in noise, crowding, and instability, combined with a lack of organization, routines, structures, and regularities (Corapci \& Wachs, 2002; Matheny, Wachs, Ludwig, \& Phillips, 1995). Household chaos has mainly been studied in nonclinical populations. There, household chaos is associated with externalizing behavior (Dumas et al., 2005) and self-regulatory deficits (Hardaway, Wilson, Shaw, \& Dishion, 2012). Household chaos is linked to children's general problem behavior over and above parenting, exacerbating the impact of poorer quality parenting (Coldwell, Pike, \& Dunn, 2006; Deater-Deckard et al., 2009). Routines and organization play an important role in structuring everyday family life (Spagnola \& Fiese, 2007), specifically for families where a child suffers from ADHD (Firmin \& Phillips, 2009). Family routines are significantly associated with both internalizing and externalizing problems in children with ADHD (Harris et al., 2014). It is more challenging for parents of children with ADHD to provide family structure and household organization than for parents of 
typically developing children (Biederman, Faraone, \& Monuteaux, 2002; Biederman et al., 1995). Furthermore, household chaos has been linked to inadequate parenting behavior, such as harsh and inconsistent behavior, less supporting reactions on children's negative emotions or low involvement in family activities (Coldwell et al., 2006; Matheny et al., 1995; Valiente, Lemery-Chalfant, \& Reiser, 2007), and has been shown to mediate the association between parental ADHD symptoms and their negative parenting (Mokrova, O'Brien, Calkins, \& Keane, 2010).

Taken together, (a) parents of children with ADHD display less adequate parenting and (b) the emotional climate within the family is more negative than in families with typically developing children. Moreover, (c) families of children with ADHD exhibit less household organization and structure than families of children without ADHD. However, little is known about the associations of parenting, emotional climate, and household chaos in families with children with ADHD compared with families without children with ADHD. Investigating the association of these constructs may provide a basis for further development of therapy approaches. As it has been found that household chaos mediates the association between parental ADHD symptoms and their negative parenting (Mokrova et al., 2010), we aimed at testing the assumption that children's ADHD symptomatology may lead to household chaos which in turn affects parenting and the emotional climate within the family. That is, we hypothesize that in families with children with ADHD, parents because of their children's symptoms have difficulties to establish and maintain structure and routines, to do the housework, or to organize family activities, all of which results in a more chaotic family environment, which in turn interferes with establishing a positive emotional climate and adequate parenting. Hence, the purpose of the current study was (a) to add to extant findings by seeking to replicate previous findings on group differences between families of children with and without ADHD regarding parenting, emotional climate, and household chaos, as well as the links between parenting and household chaos using a German sample, and (b) to examine whether negative emotional climate is related to inadequate parenting and household chaos. Moreover, taking into account research suggesting indirect effects of parental ADHD symptomatology on inadequate parenting via household chaos, (c) we examined whether these indirect effects are valid for the relation between children's ADHD symptomatology and inadequate parenting, too. Finally, (d) we investigated whether a similar indirect effect can be found for the relation between children's ADHD and negative emotional climate via household chaos. Figure 1 illustrates the assumed indirect effects of ADHD on (a) the different parenting dimensions and (b) the EE categories via household chaos.

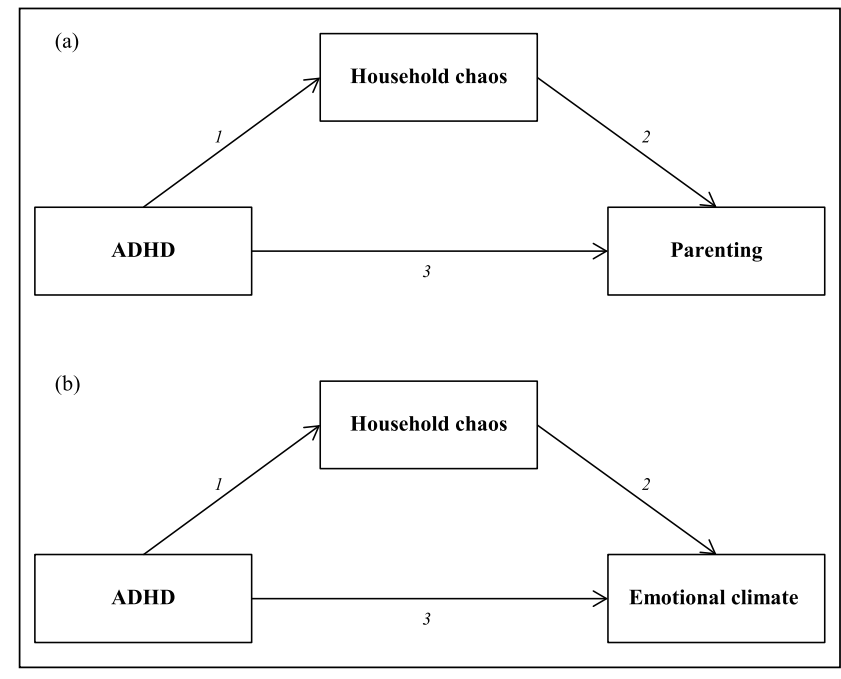

Figure I. Mediation models showing the relation between ADHD and (a) parenting or (b) emotional climate with household chaos as mediator.

Note. The arrows present the model assumptions: ( $\mathrm{I}$ ) a relation between ADHD and household chaos, (2) a relation between household chaos and parenting or emotional climate, and (3) a possible direct effect of ADHD on parenting or emotional climate without considering the mediator. The indirect effect of ADHD on parenting or emotional climate via household chaos is estimated as the product of Paths I and 2 .

\section{Method}

\section{Participants}

Participants for this study were 84 parent-child dyads (10 fathers) from a larger sample of families who took part in a larger German study. Children were recruited from schools, local child psychiatric outpatient centers, and a clinic for child and adolescent psychiatry. Inclusion criteria for all children were (a) age between 7 and 13 years; (b) an IQ $\geq$ 70 ; (c) no pervasive developmental disorder, autism, or psychotic disorders; and (d) a birth weight $\geq 2,500 \mathrm{~g}$. With all parents we conducted a structured interview for psychiatric disorders in children, done by expert clinician raters (Kinder-DIPS; Schneider, Unnewehr, \& Margraf, 2009) and asked the parents to complete the FBB-ADHS (Döpfner, Lehmkuhl, \& Steinhausen, 2006; cutoff: Stanine score $>6$ ), a German checklist addressing the symptom criteria for ADHD according to Diagnostic and Statistical Manual of Mental Disorders (4th ed., text rev.; DSM-IV-TR; American Psychiatric Association [APA], 2000) and International Classification of Diseases (10th rev.; ICD-10; German ed.: Dilling, 2008). With a total of 20 items, it accounts for differences between the two diagnostic manuals. Each item is rated on a 4-point Likert scale $(0=$ does not fit at all to $4=$ fits extremely well), with higher scores indicating more severe symptoms. Children were included in the ADHD group if they had a previous clinical ADHD diagnosis according to ICD-10, which was corroborated by above 
Table I. Participant Demographic and Clinical Characteristics.

\begin{tabular}{|c|c|c|c|c|}
\hline \multirow[b]{2}{*}{ Variable } & \multicolumn{2}{|c|}{$\operatorname{ADHD}(n=31)$} & \multicolumn{2}{|c|}{ Control $(n=53)$} \\
\hline & $M(S D)$ & $\%$ & $M(S D)$ & $\%$ \\
\hline Age (years) & $10.25(1.70)$ & & $9.86(1.51)$ & \\
\hline Child sex (male) & & 81.6 & & 69.8 \\
\hline $\begin{array}{l}\text { Socioeconomic } \\
\text { status }\end{array}$ & 14.96 (4.05) & & I5.88 (3.45) & \\
\hline \multicolumn{5}{|l|}{ ADHD diagnosis } \\
\hline Combined type & & 38.7 & & \\
\hline Inattentive type & & 38.7 & & \\
\hline $\begin{array}{l}\text { Hyperactive/ } \\
\text { impulsive type }\end{array}$ & & 22.6 & & \\
\hline \multicolumn{5}{|l|}{ Comorbidity } \\
\hline $\begin{array}{l}\text { Oppositional } \\
\text { defiant disorder }\end{array}$ & & 35.5 & & 3.8 \\
\hline Tic disorder & & 16.1 & & 1.9 \\
\hline Major depression & & 1.9 & & \\
\hline Current medication $^{a}$ & & 64.5 & & \\
\hline $\begin{array}{l}\text { Current or past } \\
\text { psychotherapy }\end{array}$ & & 29.0 & & \\
\hline $\begin{array}{l}\text { Cognitive } \\
\text { behavioral } \\
\text { therapy }\end{array}$ & & 22.6 & & \\
\hline $\begin{array}{l}\text { Psychoanalytical } \\
\text { therapy }\end{array}$ & & 6.4 & & \\
\hline
\end{tabular}

${ }^{a}$ All participants on medication were taking methylphenidate.

cutoff scores in the clinical interview and the overall score of the German ADHD symptom checklist. Children were only included in the control group if they never had a clinical ADHD diagnosis and if scores in the standardized interview and the overall scale of the ADHD symptom checklist remained below the cutoff values. For the ADHD group, 31 children met inclusion criteria and 53 children were assigned to the control group. Participant characteristics are presented in Table 1 . The groups did not differ regarding age, $t(82)=1.11, p=.272$; sex, $\chi^{2}(1)=1.19, p=.276$; and socioeconomic status (SES), $t(68)=-1.01, p=.318$.

\section{Measures}

Parenting. Parenting was assessed using five subscales of the German modified version of the Alabama Parenting Questionnaire (DEAPQ-EL-GS; Reichle \& Franiek, 2009; original version: Frick, 1991). We used the subscales Positive Parenting (six items, e.g., "You let your child know when he/she is doing a good job with something."), Parental Involvement (six items, e.g., "You play games or do other fun things with your child"), Poor Monitoring (six items, e.g., "You get so busy that you forget where your child is and what he/she is doing."), Corporal Punishment (four items, e.g., "You spank your child with your hand."), and Inconsistent Discipline (six items, e.g., "The punishment you give your child depends on your mood."). Items were rated on a 5 -point scale $(1=$ never to $5=$ always $)$ by the parent.

Emotional climate. To assess emotional climate, the Preschool Five Minute Speech Sample (PFMSS; Daley et al., 2003) was conducted with one parent and recorded as a digital audio file. The PFMSS is a modification of the Five Minute Speech Sample (FMSS; Magaña et al., 1986), which was developed for the use with adults. In the PFMSS, parents are instructed to talk about their child expressing their thoughts, feelings, and attitudes toward the child, and explaining their relationship for $5 \mathrm{~min}$ without interruption. The speech samples were coded by two independent and blind raters using a coding scheme modified for child populations, which was shown to have good to acceptable coderecode, interrater, and test reliability, as well as satisfactory construct and discriminant validity (Daley et al., 2003). The original coding scheme has been revised to overcome developmental problems of child populations (e.g., considering parental warmth) and has been used with school children before (Cartwright et al., 2011; Yelland \& Daley, 2009). Ratings based on content and tone of voice were made for five categories: initial statement (IS), relationship (REL), warmth (WAR), positive (PC), and critical comments (CC) with the first three global categories rated positive, neutral, or negative (IS, REL), respectively high, moderate, or low (WAR) for the entire speech sample, whereas the latter two (PC, CC) were frequency counts. With IS, the first thought expressed by the parent about their child is rated. REL describes the quality of the relationship between parent and child and joint activities. WAR assesses the intensity of sentiment or feeling the parent expresses about the child. In CC, statements which criticize the child are counted whereas PC assesses statements of appreciation, approval, and praise. While earlier research often classified EE dichotomously as either high or low, more recent studies make use of a more detailed analysis of the individual components of EE (Cartwright et al., 2011; Daley et al., 2003), so that we differentiated the different categories of the PFMSS in our analyses. The authors received a rating training by David Daley and trained two raters (graduate students) in turn on training audio files until a good interrater reliability (at least $\kappa>.75$ for each category) was achieved.

Household chaos. We assessed the degree of household chaos with the Confusion, Hubbub, And Order Scale (CHAOS; Matheny et al., 1995). The scale consists of 15 items, such as "You can't hear yourself think in our home," being answered by the parent using a true/false format according to the original publication of Matheny et al. (1995). A total chaos score (range 0-15) was generated by summing the responses for the items with a higher score 
representing more chaotic and less organized characteristics of the home.

\section{Procedure}

The data collection took place in laboratories at a German research center. Parent and child received detailed information sheets and expressed their consent to participate. Parents completed the PFMSS before the questionnaires assessing parenting and household chaos were presented, while children performed a variety of other tasks in another room. The study was approved by both the local psychological and medical ethics committees.

\section{Data Analysis}

Interrater reliability for the two independent raters was examined in the preliminary analyses using Cohen's weighted kappa for the global ratings of IS, REL, and WAR and Spearman rho correlations for PC and CC. To compare ADHD and control groups on the continuous variables (parenting dimensions and household chaos), independent $t$-tests were conducted, while the ordinal variables (global EE ratings, PC, and CC) were examined through MannWhitney $U$-tests. Correlations between ADHD, parenting, EE, and household chaos were analyzed using Pearson correlations for the continuous and Spearman rho correlations for the ordinal variables. Several mediation analyses were conducted to analyze whether ADHD is directly related to the different parenting dimensions and EE categories, or indirectly via household chaos. In each of these analyses, three separate regression models were calculated (Baron \& Kenny, 1986). In the first model, the regression weight for the independent variable (ADHD) on the dependent variable (parenting dimensions/EE categories) represented the total effect of the independent variable (ADHD). A second model estimated the relation between the independent variable (ADHD) and the potential mediator (household chaos). In the final model, the dependent variable was predicted simultaneously by the independent variable and the mediator (Figure 1). Confidence intervals for the indirect effect were calculated based on a bias-corrected bootstrap method (Preacher \& Hayes, 2004). Importantly, these indirect effects can be present even in the absence of a total effect (Rucker, Preacher, Tormala, \& Petty, 2011). Mediation analyses were carried out in SPSS using the Process Macro (Hayes, 2013).

\section{Results}

\section{Preliminary Analyses}

The interrater reliability for the PFMSS categories IS $(\kappa=$ $.83)$, REL $(\kappa=.88)$, PC $(\rho=.86)$, and CC $(\rho=.74)$ were
Table 2. Means and Standard Deviations on APQ Dimensions, PFMSS Categories, and CHAOS for the ADHD and Control Group.

\begin{tabular}{|c|c|c|c|c|c|c|c|}
\hline \multirow[b]{2}{*}{ Measure } & \multicolumn{2}{|c|}{$\begin{array}{l}\text { ADHD } \\
(n=3 I)\end{array}$} & \multicolumn{2}{|c|}{$\begin{array}{l}\text { Control } \\
(n=53)\end{array}$} & \multirow[b]{2}{*}{$t / U$} & \multirow[b]{2}{*}{$d f$} & \multirow[b]{2}{*}{$p$} \\
\hline & $M$ & $S D$ & $M$ & $S D$ & & & \\
\hline $\begin{array}{l}\text { APQ-Positive } \\
\text { Parenting }\end{array}$ & 25.93 & 2.84 & 26.85 & 2.45 & -1.54 & 81 & .127 \\
\hline $\begin{array}{l}\text { APQ-Parental } \\
\text { Involvement }\end{array}$ & 23.70 & 2.98 & 24.57 & 2.72 & -1.35 & 81 & .182 \\
\hline $\begin{array}{l}\text { APQ-Poor } \\
\text { Monitoring }\end{array}$ & 8.97 & 3.45 & 7.19 & 1.89 & 3.02 & 80 & .003 \\
\hline $\begin{array}{l}\text { APQ-Corporal } \\
\text { Punishment }\end{array}$ & 6.17 & 2.10 & .18 & 1.62 & 2.37 & 79 & .020 \\
\hline $\begin{array}{l}\text { APQ- } \\
\text { Inconsistent } \\
\text { Discipline }\end{array}$ & 15.10 & 4.79 & 14.00 & 3.81 & 1.14 & 79 & .258 \\
\hline CHAOS & .33 & .19 & .20 & .14 & 3.59 & 82 & .001 \\
\hline PFMSS-IS & $36.56^{\mathrm{a}}$ & & $44.50^{\mathrm{a}}$ & & 637.50 & & .102 \\
\hline PFMSS-REL & $45.34^{\mathrm{a}}$ & & $39.17^{\mathrm{a}}$ & & 671.50 & & .045 \\
\hline PFMSS-PC & $38.87^{\mathrm{a}}$ & & $43.10^{\mathrm{a}}$ & & 709.00 & & .435 \\
\hline PFMSS-CC & $58.77^{\mathrm{a}}$ & & $31.00^{\mathrm{a}}$ & & 255.00 & & .000 \\
\hline
\end{tabular}

Note. $\mathrm{APQ}=$ Alabama Parenting Questionnaire; PFMSS = Preschool Five Minute Speech Sample; CHAOS = Confusion, Hubbub, and Order Scale; IS = initial statement; REL = relationship; $\mathrm{PC}=$ positive comments; $\mathrm{CC}=$ critical comments.

${ }^{a}$ Mean ranks.

${ }^{\dagger} p<.10 .{ }^{*} p<.05 . *_{p}<.01 . *^{* *} p<.001$.

good to very good, but poor for WAR $(\kappa=.12)$. Further inspection revealed that one of the raters rated WAR as moderate in all but two of the cases, and also the other rater rated WAR high in most cases, thereby biasing the interrater reliability. Although the absolute concordance was $75.4 \%$, which is still satisfying, we decided to skip the WAR category for the further analyses.

\section{Main Analyses}

First, we examined group differences in parenting, emotional climate, and household chaos. Table 2 contains means, standard deviations, and mean ranks for the ADHD and control group for all measures used in this study.

Regarding the APQ subscales, parents of children with ADHD reported poorer monitoring, $t(80)=3.02, p=.001$, $d=.69$, and more corporal punishment, $t(79)=2.37$, $p=.020, d=.55$, than parents of children without ADHD. No group differences were found for positive parenting, $t(81)=-1.54, p=.127$; inconsistent discipline, $t(79)=1.14$, $p=.258$; and parental involvement, $t(81)=-1.35, p=.182$. Concerning the PFMSS categories, parents of children with ADHD expressed significantly more CC $(U=255.00, p=$ $.000, r=.57)$, but reported better REL $(U=671.50, p=.045$, $r=.22)$. Regarding IS $(U=637.50, p=.102)$ and PC 
Table 3. Summary of Intercorrelations for Diagnosis, Symptom Severity, APQ Dimensions, PFMSS Categories, and CHAOS.

\begin{tabular}{|c|c|c|c|c|c|c|c|c|c|c|c|c|c|}
\hline \multicolumn{2}{|c|}{ Measure } & \multirow{2}{*}{$\frac{1}{-}$} & \multirow[t]{2}{*}{2} & \multirow[t]{2}{*}{3} & \multirow[t]{2}{*}{4} & \multirow[t]{2}{*}{5} & \multirow[t]{2}{*}{6} & \multirow[t]{2}{*}{7} & \multirow[t]{2}{*}{8} & \multirow[t]{2}{*}{9} & \multirow[t]{2}{*}{10} & \multirow[t]{2}{*}{11} & \multirow[t]{2}{*}{12} \\
\hline $\mathrm{I}$. & Diagnosis & & & & & & & & & & & & \\
\hline 2. & FBB-ADHS & $.84^{* *}$ & - & & & & & & & & & & \\
\hline 3. & APQ-Positive Parenting & -.14 & $.25^{*}$ & - & & & & & & & & & \\
\hline 4. & APQ-Parental Involvement & -.14 & -.16 & $.29 * *$ & - & & & & & & & & \\
\hline 5. & APQ-Poor Monitoring & $.30 * *$ & $.33^{* *}$ & $-.38 * *$ & $-.34 * *$ & - & & & & & & & \\
\hline 6. & APQ-Corporal Punishment & $.25^{*}$ & $.31 * *$ & $-.23 *$ & $-.40 * *$ & $.27^{*}$ & - & & & & & & \\
\hline 7. & APQ-Inconsistent Discipline & .09 & .11 & -.17 & $-.23 *$ & $.33^{* *}$ & $.30 * *$ & - & & & & & \\
\hline 8. & PFMSS-IS & -.18 & -.06 & -.03 & .12 & -.01 & .02 & .06 & - & & & & \\
\hline 9. & PFMSS-REL & $.22 *$ & $.36 * *$ & $-.24 *$ & -.06 & $.25^{*}$ & $.22^{*}$ & .13 & .20 & - & & & \\
\hline 10. & PFMSS-PC & -.09 & -.17 & $.33 * *$ & .11 & $-.39 * *$ & $-.26 *$ & .07 & $-.29 * *$ & $-.29 * *$ & - & & \\
\hline II. & PFMSS-CC & $.58^{* *}$ & $.54 * *$ & $-.34 * *$ & $-.30 *$ & $.28^{*}$ & $.34 * *$ & .04 & .10 & $.39 * *$ & $-.24 *$ & - & \\
\hline 12. & CHAOS & $.35^{* *}$ & $.43^{* *}$ & $-.33 * *$ & $-.21^{\dagger}$ & $.23 *$ & $.4 I^{* *}$ & $.31 * *$ & .14 & $.26^{*}$ & -.07 & $.28^{*}$ & - \\
\hline
\end{tabular}

Note. APQ = Alabama Parenting Questionnaire; PFMSS = Preschool Five Minute Speech Sample; CHAOS = Confusion, Hubbub, and Order Scale; FBB$\mathrm{ADHS}=$ German ADHD symptom checklist; IS = initial statement; REL = relationship; $\mathrm{PC}=$ positive comments; $\mathrm{CC}=$ critical comments.

${ }^{\dagger} p<.10 . * p<.05 . * * p<.01 . * * * p<.001$.

$(U=709.00, p=.435)$, the groups did not differ significantly. Parents of children with ADHD reported more household chaos, $t(82)=3.59, p=.001, d=.81$, than parents of children without ADHD.

The correlations between all dependent variables are reported in Table 3 . The PFMSS categories correlated differentially with parenting: $\mathrm{CC}$ was negatively correlated with positive parenting and involvement and positively correlated with poor monitoring and corporal punishment. There was no significant correlation between $\mathrm{CC}$ and inconsistent discipline. REL was negatively correlated with positive parenting and positively correlated with poor monitoring and corporal punishment. There were no significant correlations between REL and the remaining parenting dimensions. PC was positively associated with positive parenting and negatively correlated with poor monitoring and corporal punishment, but not significantly associated with inconsistent discipline and parental involvement.

Household chaos was negatively associated with positive parenting, and positively associated with inconsistent discipline, poor monitoring, and corporal punishment. It was marginally negatively associated with parental involvement. Household chaos was positively correlated with the PFMSS categories REL and CC, but not with IS and PC.

A closer comparison of the correlations between the measured variables with (a) the categorical diagnosis of ADHD/non-ADHD and (b) the continuous FBB-ADHS scores representing the symptom severity revealed higher associations for the latter. This finding is not surprising, as it has been shown that effect sizes are generally larger for continuous measures compared with measures that have been dichotomized (MacCallum, Zhang, Preacher, \& Rucker, 2002). Based on these results, we decided to conduct the final set of analyses, in which we tested whether the relation between children's ADHD symptomatology and inadequate parenting and negative emotional climate is mediated through household chaos, with FBBADHS scores as dependent variable. Table 4 contains the results of the mediation analyses for the parenting dimensions and EE categories. In a first step, household chaos was regressed on ADHD symptom severity, and symptom severity predicted household chaos, $b=0.11, t(81)=4.70$, $p<.001$. In the second step, positive parenting was regressed on symptom severity, and symptom severity predicted positive parenting, $b=-0.89, t(81)=-2.28, p=$ .025 . In the third step, positive parenting was predicted simultaneously by ADHD and household chaos. With both variables being included in the regression equation, household chaos remained significant, $b=-4.15, t(80)=$ $-2.32, p=.023$, whereas symptom severity did not, $b=$ $-0.43, t(80)=-1.00, p=.321$. A bias-corrected bootstrap $95 \%$ confidence interval (CI) based on 20,000 bootstrap samples indicated a significant indirect effect of ADHD on positive parenting through household chaos, $b=-0.46$, $95 \%$ CI $[-1.07,-0.01]$. Together, the three regression models demonstrated a complete mediation of the relation between symptom severity and positive parenting through household chaos. We found a complete mediation through household chaos also for the relation between symptom severity and corporal punishment. For inconsistent discipline, we found a significant indirect effect via household chaos, even though the total effect was not significant. For parental involvement and poor monitoring, no significant indirect effects were found. However, regarding emotional climate, none of the indirect effects for any of the PFMSS categories reached statistical significance. Hence, there did not seem to be an indirect effect of ADHD on emotional climate through household chaos. 
Table 4. Summary of the Mediation Analyses.

\begin{tabular}{|c|c|c|c|c|c|c|c|}
\hline IV & DV & MED & $\begin{array}{l}\text { Effect IV } \rightarrow \\
\quad \text { MED (a) }\end{array}$ & $\begin{array}{l}\text { Effect MED } \rightarrow \\
\quad \text { DV (b) }\end{array}$ & $\begin{array}{c}\text { Direct } \\
\text { effect }\left(c^{c}\right)\end{array}$ & $\begin{array}{l}\text { Indirect effect } \\
\qquad(\mathrm{a} \times \mathrm{b})\end{array}$ & $\begin{array}{l}\text { Total } \\
\text { effect }\end{array}$ \\
\hline \multirow[t]{9}{*}{ FBB-ADHS } & APQ-Positive Parenting & CHAOS & $0.11 * * *$ & $-4.15^{* *}$ & -0.43 n.s. & $-0.46 *$ & $-0.89 *$ \\
\hline & APQ-Parental Involvement & & $0.11 * * *$ & -2.82 n.s. & -0.31 n.s. & -0.31 n.s. & -0.63 n.s. \\
\hline & APQ-Poor Monitoring & & $0.11 * * *$ & I.53 n.s. & $1.05^{*}$ & 0.17 n.s. & $1.22 * *$ \\
\hline & APQ-Corporal Punishment & & $0.11 * * *$ & $3.60 * *$ & 0.42 n.s. & $0.39 *$ & $0.80 * *$ \\
\hline & APQ-Inconsistent Discipline & & $0.11 * * *$ & $7.80 *$ & -0.22 n.s. & $0.85^{*}$ & 0.62 n.s. \\
\hline & PFMSS-IS & & $0.11 * * *$ & 0.45 n.s. & -0.10 n.s. & 0.05 n.s. & 0.07 n.s. \\
\hline & PFMSS-REL & & $0.11 * * *$ & 0.21 n.s. & $0.09^{\dagger}$ & 0.02 n.s. & $0.11 *$ \\
\hline & PFMSS-PC & & $0.11 * * *$ & -0.82 n.s. & -0.26 n.s. & -0.08 n.s. & -0.35 n.s. \\
\hline & PFMSS-CC & & $0.11 * * *$ & 0.72 n.s. & $0.97 * * *$ & 0.07 n.s. & $1.04 * * *$ \\
\hline
\end{tabular}

Note. Number of Bootstrap resamples: 20,000. IV = independent variable; $D V=$ dependent variable; $M E D=$ mediator; FBB-ADHS = German $A D H D$ symptom checklist; APQ = Alabama Parenting Questionnaire; CHAOS = Confusion, Hubbub, and Order Scale; PFMSS = Preschool Five Minute Speech Sample; IS = initial statement; REL = relationship; $\mathrm{PC}=$ positive comments; $\mathrm{CC}=$ critical comments; n.s. $=$ not statistically significant. ${ }^{\dagger} p<.10 . * p<.05 . * * p<.01 . * * * p<.001$.

\section{Discussion}

In the reported study, we aimed not only at assessing the differences between families with and without ADHD regarding parenting, emotional climate, and household chaos which have been highlighted in previous studies, but also at assessing the relationship between these variables in families with ADHD compared with families with typically developing children.

Parents of children with ADHD reported poorer monitoring and more corporal punishment compared with the control group in our study, similar to previous studies (Deault, 2010; Ellis \& Nigg, 2009; Tripp et al., 2007) that found more inadequate parenting behavior characterized by poorer monitoring, less support, more frequent use of physical discipline, and a lack of positive parenting in families with children with ADHD. However, contrary to the literature, parents of children with ADHD did not report less positive, less consistent parenting or lower involvement compared with parents of typically developing children. It might be the case that the symptom severity in our sample is lower than in comparable studies. This assumption is supported by the fact that we did not study an inpatient sample but participants who were in outpatient treatment or after completing the diagnostic process (Sciberras et al., 2013). Consequently, the participating parents may already have greater knowledge of parenting practices. Another possible explanation is that both our groups came from high SES households, which typically show more adequate parenting, especially less inconsistent parenting (Hoff, Laursen, \& Tardif, 2002). Furthermore, the results might reflect how parents of children with ADHD complete self-report measures assessing competences, rather than indicating a particular strength in certain parenting dimensions: As many parents of children with ADHD may have ADHD themselves (Chronis et al., 2003) and adult ADHD has been found to be associated with overestimation of competence (Jiang \& Johnston, 2012), parents of children in this study may have difficulties to report their own behavior and therefore overestimate their parenting competence. This explanation is in line with findings of an overestimation of positive parenting across mothers and fathers with ADHD symptoms compared with observations in parent-child interactions (Lui, Johnston, Lee, \& Lee-Flynn, 2013).

In the present study, parents of children with ADHD reported more critical comments, which is in line with previous findings on a more negative emotional climate in families with children with ADHD (Cartwright et al., 2011; Daley et al., 2003; Musser et al., 2016). However, the better relationship reported by parents of children with ADHD was unexpected and not consistent with the literature reporting poorer and more tensed relationships within families with children with ADHD (Cartwright et al., 2011; Daley et al., 2003). Again, a possible explanation for this finding may be that some of the participating children were already enrolled in a therapeutic treatment: Treating children with ADHD with stimulants, such as Methylphenidate, often leads to a significant improvement of the parent-child relationship (MTA Cooperative Group, 1999). In addition, behavioral parent training (BPT) also focuses on strengthening the parent-child relationship. BPT teaches parents to identify their child's problematic behaviors and modify unwanted behavior through time-out or withholding privileges, and rewarding adequate behavior through positive attention or rewards (Chronis, Chacko, Fabiano, Wymbs, \& Pelham, 2004; Evans, Owens, \& Bunford, 2014; Fabiano et al., 2009). Furthermore, the assessment of the relationship between parent and child is based on parental statements about joint adventures and how the parent describes the quality of the relationship. Since one part of the instruction for the speech sample is to talk about how parent and child get along with each other, this aspect is asked for more 
directly as compared with the other categories and therefore might result in a more subjective estimation as it may be confounded by social desirability. Regarding the nonconsistent finding of no differences in IS, further analyses showed that IS was rated neutral for most speech samples as they normally started with telling the child's name and age. In contrast to previous studies (Cartwright et al., 2011; Daley et al., 2003), we did not find differences regarding positive comments. This may be due to the small sample size which may have underestimated the effect (Rucker et al., 2011). Consistent with the literature is the group difference regarding household organization in our study showing higher household chaos in families with children with ADHD as compared with families with typically developing children (Biederman et al., 2002; Harris et al., 2014).

The core aim of the current study was to examine the associations between parenting, emotional climate, and household chaos in families with ADHD, a new research question which has not been investigated before. In the correlation analyses, we found negative correlations between $\mathrm{CC}$ and positive parenting and involvement, and positive correlations between $\mathrm{CC}$ and poor monitoring and corporal punishment. In line with this, we found positive correlations between $\mathrm{PC}$ and positive parenting and negative correlations between $\mathrm{PC}$ and poor monitoring and corporal punishment. These associations between parenting and positive and critical comments suggest that parents who show inadequate parenting also talk about their children in a critical way and vice versa which indicates the importance of improving parenting practices. A higher REL was negatively correlated with positive parenting and positively associated with poor monitoring and corporal punishment, contrary to our expectations. This finding may be explained by the group difference in REL with higher scores in the ADHD group. Inconsistent discipline was not associated with any of the EE categories, which might be due to the low inconsistency scores throughout our sample. Household chaos was negatively associated with positive parenting and positively correlated with poor monitoring, corporal punishment, and inconsistent discipline, which mostly supports the previously established associations between inadequate parenting, such as less positive parenting, lower involvement and more inconsistent parenting, and high household chaos (Coldwell et al., 2006; Valiente et al., 2007). Furthermore, household chaos was positively associated with $\mathrm{CC}$ and unexpectedly also with REL, while it was not associated with IS or PC. Taken together, it seems that household chaos does not play a strong role in affecting the attitudes and feelings parents have toward their children, but is related to parenting practice only.

Our final aim was to analyze indirect effects from ADHD to parenting and the emotional climate through household chaos. For the relation between ADHD and positive parenting, corporal punishment, and inconsistent discipline, we found mediation effects through household chaos, which means that deficits in household organization were associated with specific parenting dimensions in families with children with ADHD. These findings are similar to previous results that showed a mediation of the association between ADHD and ineffective parenting through household chaos (Mokrova et al., 2010). For the EE categories, no indirect effects were found in our study. Clearly, these results demonstrated that household chaos plays a role in the relation between children's ADHD symptomatology and ineffective parenting, as it seems to work as a mechanism through which children's ADHD symptoms lead to ineffective parenting. However, a chaotic home does not seem to influence the association between the child's ADHD and negative emotional climate. It might be that in a very chaotic and unstructured home, it is difficult for parents to follow through with an authoritative parenting, but they still like and enjoy being around their children. The APQ measures parenting behavior whereas the PFMSS assesses a description of the parent-child relationship, and the child's behavior and personality, about which parents can report freely and without any direct questions, which allows a more subjective perspective.

The present study has some limitations. Although we used speech samples to assess EE as a more objective method than questionnaires and thus, effort was made to reduce informant effects, the information about parenting, emotional climate, and household chaos was rated only by parents themselves. Hence, the main limitation of the study is shared method variance. Future studies might want to use child ratings as well as objective measures such as observations of parenting behavior in addition as they may be more accurate than self-reports and may prevent the previously mentioned problem of overestimation of competencies (Lui et al., 2013; Zaslow et al., 2006). Also obtaining information from both parents should be considered, as there are gender differences regarding parenting practices (Simons \& Conger, 2007) and emotional expression (Chaplin, Cole, \& Zahn-Waxler, 2005). Another restriction is the cross sectional design that is generally not suitable to test causal assumptions of a mediation model. Thus, the directions of influence need to be considered critical as child's ADHD symptomatology might also be influenced by a chaotic home, inadequate parenting, or negative emotional climate.

Moreover, deficient parenting and household chaos may be caused by a common unmeasured confounding variable, as for instance parental psychopathology, which was not taken into account in the present study. As parents of children with ADHD are more likely to have ADHD or other psychological disorder themselves (Chronis et al., 2003), and as parental ADHD as well as other disorders, such as depression, may affect parenting behavior and emotional climate within families (Deault, 2010), future studies should 
include parental psychopathology to allow more detailed conclusions about the relationship between children's ADHD and parenting.

The finding of the indirect effect of ADHD on parenting through household chaos establishes new intervention approaches. Besides improving parenting skills, the relationship between child and parents, or the emotional climate within the family as it is already part of some cognitive-behavioral training programs for parents of children with ADHD (e.g., Barkley, 2013; Evans et al., 2014; Fabiano et al., 2009), future research should focus on designing parent trainings able to improve family functioning by reducing household chaos and improving the household structure, for instance by strengthening routines, rituals, and rules and establishing a better organization. One could think of interventions that consist of psychoeducation about the importance of structure and order, and also of behavioral elements, such as precise schedules for the children's activities. Moreover, parents could aim to reduce background noises and crowding by switching off radios and TVs, taking phone calls in closed rooms, or receiving guests only during certain times, and to create a quiet environment for the child, for example, by having the child do the homework alone in their room and not in a common area.

In conclusion, the present study replicated past findings that household chaos interferes with parenting and with emotional climate in families with children with ADHD. By showing that the relation between ADHD and parenting is influenced by the amount of household chaos, we have extended previous research. Future research is needed to address (a) the causality of the examined constructs (e.g., by designing longitudinal studies), and (b) potential confounding variables (e.g., parental ADHD symptoms).

\section{Declaration of Conflicting Interests}

The author(s) declared no potential conflicts of interest with respect to the research, authorship, and/or publication of this article.

\section{Funding}

The author(s) disclosed receipt of the following financial support for the research, authorship, and/or publication of this article: This research was supported by the Hessian initiative for the development of scientific and economic excellence (LOEWE).

\section{References}

American Psychiatric Association. (2000). Diagnostic and statistical manual of mental disorders (4th ed., text rev.). Washington, DC: Author.

Asarnow, J. R., Goldstein, M. J., Tompson, M., \& Guthrie, D. (1993). One-year outcomes of depressive disorders in child psychiatric in-patients: Evaluation of the prognostic power of a brief measure of expressed emotion.
Journal of Child Psychology and Psychiatry, 34, 129-137. doi:10.1111/j.1469-7610.1993.tb00975.x

Baker, B. L., Heller, T. L., \& Henker, B. (2000). Expressed emotion, parenting stress, and adjustment in mothers of young children with behavior problems. Journal of Child Psychology and Psychiatry, 41, 907-915. doi:10.1111/1469-7610.00678

Barkley, R. A. (2013). Defiant children: A clinician's manual for parent treating (3rd ed.). New York, NY: Guilford Press.

Baron, R. M., \& Kenny, D. A. (1986). The moderator-mediator variable distinction in social psychological research: Conceptual, strategic, and statistical considerations. Journal of Personality and Social Psychology, 51, 1173-1182. doi:10.1037/0022-3514.51.6.1173

Benard, B. (1991). Fostering resiliency in kids: Protective factors in the family, school, and community. Portland, OR Northwest Regional Educational Laboratory.

Biederman, J., Faraone, S. V., \& Monuteaux, M. C. (2002). Impact of exposure to parental attention-deficit hyperactivity disorder on clinical features and dysfunction in the offspring. Psychological Medicine, 32, 817-827. doi:10.1017/ S0033291702005652

Biederman, J., Milberger, S., Faraone, S. V., Kiely, K., Guite, J., Mick, E., ... Reed, E. (1995). Family-environment risk factors for attention-deficit hyperactivity disorder: A test of Rutter's indicators of adversity. Archives of General Psychiatry, 52, 464-470. doi:10.1001/archpsyc.1995.03950180050007

Brown, G. W., \& Rutter, M. (1966). The measurement of family activities and relationships: A methodological study. Human Relations, 19, 241-263. doi:10.1177/001872676601900301

Butzlaff, R. L., \& Hooley, J. M. (1998). Expressed emotion and psychiatric relapse: A meta-analysis. Archives of General Psychiatry, 55, 547-552. doi:10.1001/archpsyc.55.6.547

Cartwright, K. L., Bitsakou, P., Daley, D., Gramzow, R. H., Psychogiou, L., Simonoff, E., . . . Sonuga-Barke, E. J. S. (2011). Disentangling child and family influences on maternal expressed emotion toward children with attention-deficit/ hyperactivity disorder. Journal of the American Academy of Child \& Adolescent Psychiatry, 50, 1042-1053. doi:10.1016/j. jaac.2011.07.006

Chaplin, T. M., Cole, P. M., \& Zahn-Waxler, C. (2005). Parental socialization of emotion expression: Gender differences and relations to child adjustment. Emotion, 5, 80-88. doi:10.1037/1528-3542.5.1.80

Chronis, A. M., Chacko, A., Fabiano, G. A., Wymbs, B. T., \& Pelham, W. E., Jr. (2004). Enhancements to the behavioral parent training paradigm for families of children with ADHD: Review and future directions. Clinical Child and Family Psychology Review, 7, 1-27.

Chronis, A. M., Lahey, B. B., Pelham, W. E., Kipp, H. L., Baumann, B. L., \& Lee, S. S. (2003). Psychopathology and substance abuse in parents of young children with attention-deficit/hyperactivity disorder. Journal of the American Academy of Child \& Adolescent Psychiatry, 42, 1424-1432. doi:10.1097/00004583-200312000-00009

Chronis, A. M., Lahey, B. B., Pelham, W. E., Jr., Williams, S. H., Baumann, B. L., Kipp, H., . . Rathouz, P. J. (2007). Maternal depression and early positive parenting predict future conduct problems in young children with attention-deficit/ 
hyperactivity disorder. Developmental Psychology, 43, 70-82. doi:10.1037/0012-1649.43.1.70

Coldwell, J., Pike, A., \& Dunn, J. (2006). Household chaosLinks with parenting and child behaviour. Journal of Child Psychology and Psychiatry, 47, 1116-1122. doi:10.1111/ j.1469-7610.2006.01655.x

Corapci, F., \& Wachs, T. D. (2002). Does parental mood or efficacy mediate the influence of environmental chaos upon parenting behavior? Merrill-Palmer Quarterly, 48, 182-201. doi:10.1353/mpq.2002.0006

Daley, D., Sonuga-Barke, E. J. S., \& Thompson, M. (2003). Assessing expressed emotion in mothers of preschool AD/ HD children: Psychometric properties of a modified speech sample. British Journal of Clinical Psychology, 42, 53-67. doi:10.1348/014466503762842011

Deater-Deckard, K., Mullineaux, P. Y., Beekman, C., Petrill, S. A., Schatschneider, C., \& Thompson, L. A. (2009). Conduct problems, IQ, and household chaos: A longitudinal multiinformant study. Journal of Child Psychology and Psychiatry, 50, 1301-1308. doi:10.1111/j.1469-7610.2009.02108.x

Deault, L. C. (2010). A systematic review of parenting in relation to the development of comorbidities and functional impairments in children with attention-deficit/hyperactivity disorder (ADHD). Child Psychiatry \& Human Development, 41, 168192. doi:10.1007/s10578-009-0159-4

Dilling, H. (Ed.). (2008). Internationale Klassifikation psychischer Störungen: ICD-10, Kapitel $V(F)$. klinisch-diagnostische Leitlinien [International classification of mental disorders: ICD-10, chapter V (F), clinical and diagnostic guidelines] (6th ed.). Bern, Switzerland: Huber.

Döpfner, M., Lehmkuhl, G., \& Steinhausen, H.-C. (2006). KIDS-1 Aufmerksamkeitsdefizit- und Hyperaktivitätsstörung $(A D H S)$ [Children diagnostic system 1. ADHD]. Göttingen, Germany: Hogrefe.

Dumas, J. E., Nissley, J., Nordstrom, A., Smith, E. P., Prinz, R. J., \& Levine, D. W. (2005). Home chaos: Sociodemographic, parenting, interactional, and child correlates. Journal of Clinical Child and Adolescent Psychology, 34, 93-104. doi:10.1207/s15374424jccp3401_9

Ellis, B., \& Nigg, J. (2009). Parenting practices and attentiondeficit/hyperactivity disorder: New findings suggest partial specificity of effects. Journal of the American Academy of Child \& Adolescent Psychiatry, 48, 146-154. doi:10.1097/ CHI.0b013e31819176d0

Evans, S. W., Owens, J. S., \& Bunford, N. (2014). Evidence-based psychosocial treatments for children and adolescents with attention-deficit/hyperactivity disorder. Journal of Clinical Child \& Adolescent Psychology, 43, 527-551. doi:10.1080/15 374416.2013.850700

Fabiano, G. A., Pelham, W. E., Coles, E. K., Gnagy, E. M., Chronis-Tuscano, A., \& O'Connor, B. C. (2009). A metaanalysis of behavioral treatments for attention-deficit/hyperactivity disorder. Clinical Psychology Review, 29, 129-140. doi:10.1016/j.cpr.2008.11.001

Firmin, M. W., \& Phillips, A. (2009). A qualitative study of families and children possessing diagnoses of ADHD. Journal of Family Issues, 30, 1155-1174. doi:10.1177/0192 513X09333709
Frick, P. J. (1991). The Alabama Parenting Questionnaire. Unpublished manuscript, University of Alabama, Department of Psychology, Tuscaloosa, USA

Hardaway, C. R., Wilson, M. N., Shaw, D. S., \& Dishion, T. J. (2012). Family functioning and externalizing behaviour among low-income children: Self-regulation as a mediator. Infant and Child Development, 21, 67-84. doi:10.1002/ icd. 765

Harpin, V. A. (2005). The effect of ADHD on the life of an individual, their family, and community from preschool to adult life. Archives of Disease in Childhood, 90(Suppl. 1), i2-i7. doi:10.1136/adc.2004.059006

Harris, A. N., Stoppelbein, L., Greening, L., Becker, S. P., Luebbe, A., \& Fite, P. (2014). Child routines and parental adjustment as correlates of internalizing and externalizing symptoms in children diagnosed with ADHD. Child Psychiatry \& Human Development, 45, 243-253. doi:10.1007/s10578-013-0396-4

Hayes, A. F. (2013). Introduction to mediation, moderation, and conditional process analysis: A regression-based approach. New York, NY: Guilford Press.

Hoff, E., Laursen, B., \& Tardif, T. (2002). Socioeconomic status and parenting. In B. Webber (Ed.), Handbook of Parenting: Vol. 2. Biology and ecology of parenting (pp. 231-252). Mahwah, NJ: Lawrence Erlbaum.

Jiang, Y., \& Johnston, C. (2012). The relationship between ADHD symptoms and competence as reported by both self and others. Journal of Attention Disorders, 16, 418-426. doi:10.1177/1087054710392541

Johnston, C. (1996). Parent characteristics and parent-child interactions in families of nonproblem children and ADHD children with higher and lower levels of oppositional-defiant behavior. Journal of Abnormal Child Psychology, 24, 85-104. doi:10.1007/BF01448375

Johnston, C., \& Mash, E. J. (2001). Families of children with attention-deficit/hyperactivity disorder: Review and recommendations for future research. Clinical Child and Family Psychology Review, 4, 183-207. doi:10.1023/A:1017592030434

Keown, L. J. (2012). Predictors of boys' ADHD symptoms from early to middle childhood: The role of father-child and mother-child interactions. Journal of Abnormal Child Psychology, 40, 569-581. doi: 10.1007/s10802-011-9586-3

Kiff, C. J., Lengua, L. J., \& Zalewski, M. (2011). Nature and nurturing: Parenting in the context of child temperament. Clinical Child and Family Psychology Review, 14, 251-301. doi:10.1007/s10567-011-0093-4

Lange, G., Sheerin, D., Carr, A., Dooley, B., Barton, V., Marshall, D., ... Doyle, M. (2005). Family factors associated with attention deficit hyperactivity disorder and emotional disorders in children. Journal of Family Therapy, 27, 76-96. doi:10.1111/ j.1467-6427.2005.00300.x

Latimer, W. W., August, G. J., Newcomb, M. D., Realmuto, G. M., Hektner, J. M., \& Mathy, R. M. (2003). Child and familial pathways to academic achievement and behavioral adjustment: A prospective six-year study of children with and without ADHD. Journal of Attention Disorders, 7, 101-116. doi: $10.1177 / 108705470300700204$

Lui, J. H., Johnston, C., Lee, C. M., \& Lee-Flynn, S. C. (2013). Parental ADHD symptoms and self-reports of positive 
parenting. Journal of Consulting and Clinical Psychology, 81, 988-998. doi:10.1037/a0033490

MacCallum, R. C., Zhang, S., Preacher, K. J., \& Rucker, D. D. (2002). On the practice of dichotomization of quantitative variables. Psychological Methods, 7, 19-40. doi:10.1037//1082989X.7.1.19

Maccoby, E. (2000). Parenting and its effects on children: On reading and misreading behavior genetics. Annual Reviews of Psychology, 51, 1-27. doi:10.1146/annurev.psych.51.1.1

Magaña, A. B., Goldstein, M. J., Karno, M., Miklowitz, D. J., Jenkins, J., \& Falloon, I. R. (1986). A brief method for assessing expressed emotion in relatives of psychiatric patients. Psychiatry Research, 17, 203-212. doi:10.1016/01651781(86)90049-1

Matheny, A. P., Wachs, T. D., Ludwig, J. L., \& Phillips, K. (1995). Bringing order out of chaos: Psychometric characteristics of the confusion, hubbub, and order scale. Journal of Applied Developmental Psychology, 16, 429-444. doi:10.1016/01933973(95)90028-4

Mokrova, I., O’Brien, M., Calkins, S., \& Keane, S. (2010). Parental ADHD symptomology and ineffective parenting: The connecting link of home chaos. Parenting: Science and Practice, 10, 119-135. doi:10.1080/15295190903212844

MTA Cooperative Group. (1999). Moderators and mediators of treatment response for children with attention-deficit/hyperactivity disorder: The multimodal treatment study of children with attention-deficit/hyperactivity disorder. Archives of General Psychiatry, 56, 1088-1096. doi:10.1001/archpsyc.56.12.1088

Musser, E. D., Karalunas, S. L., Dieckmann, N., Peris, T. S., \& Nigg, J. T. (2016). Attention-deficit/hyperactivity disorder developmental trajectories related to parental expressed emotion. Journal of Abnormal Psychology, 125, 182-195. doi:10.1037/abn0000097

Olson, S. L., Bates, J. E., Sandy, J. M., \& Lanthier, R. (2000). Early developmental precursors of externalizing behavior in middle childhood and adolescence. Journal of Abnormal Child Psychology, 28, 119-133. doi:10.1023/A:1005166629744

Peris, T. S., \& Baker, B. L. (2000). Applications of the expressed emotion construct to young children with externalizing behavior: Stability and prediction over time. Journal of Child Psychology and Psychiatry, 41, 457-462. doi:10.1111/14697610.00630

Peris, T. S., \& Miklowitz, D. J. (2015). Parental expressed emotion and youth psychopathology: New directions for an old construct. Child Psychiatry \& Human Development, 46, 863873. doi:10.1007/s10578-014-0526-7

Preacher, K. J., \& Hayes, A. F. (2004). SPSS and SAS procedures for estimating indirect effects in simple mediation models. Behavior Research Methods, Instruments, \& Computers, 36, 717-731. doi:10.3758/BF03206553

Przeworski, A., Zoellner, L. A., Franklin, M. E., Garcia, A., Freeman, J., March, J. S., \& Foa, E. B. (2012). Maternal and child expressed emotion as predictors of treatment response in pediatric obsessive-compulsive disorder. Child Psychiatry \& Human Development, 43, 337-353. doi:10.1007/s10578-011-0268-8

Reichle, B., \& Franiek, S. (2009). Erziehungsstil aus Elternsicht: Deutsche erweiterte Version des Alabama Parenting
Questionnaire für Grundschulkinder (DEAPQ-EL-GS) [Selfreported parenting style - German extended version of the Alabama Parenting Questionnaire for Elementary School Age Children]. Zeitschrift für Entwicklungspsychologie und Pädagogische Psychologie, 41, 12-25.

Rucker, D. D., Preacher, K. J., Tormala, Z. L., \& Petty, R. E. (2011). Mediation analysis in social psychology: Current practices and new recommendations. Social and Personality Psychology Compass, 5, 359-371. doi:10.1111/j.1751-9004.2011.00355.x

Scaramella, L. V., Conger, R. D., \& Simons, R. L. (1999). Parental protective influences and gender-specific increases in adolescent internalizing and externalizing problems. Journal of Research on Adolescence, 9, 111-141.

Schneider, S., Unnewehr, S., \& Margraf, J. (Eds.). (2009). KinderDIPS: Diagnostisches Interview bei psychischen Störungen im Kindes- und Jugendalter [Structured child psychiatric interview]. Berlin, Germany: Springer.

Sciberras, E., Efron, D., Schilpzand, E. J., Anderson, V., Jongeling, B., Hazell, P., . . . Nicholson, J. M. (2013). The Children's Attention Project: A community-based longitudinal study of children with ADHD and non-ADHD controls. BMC Psychiatry, 13, Article 18. doi:10.1186/1471-244X-13-18

Simons, L. G., \& Conger, R. D. (2007). Linking mother-father differences in parenting to a typology of family parenting styles and adolescent outcomes. Journal of Family Issues, 28, 212-240. doi:10.1177/0192513X06294593

Sonuga-Barke, E. J. S., Cartwright, K. L., Thompson, M. J., Brown, J., Bitsakou, P., Daley, D., . . Simonoff, E. (2013). Family characteristics, expressed emotion, and attention-deficit/hyperactivity disorder. Journal of the American Academy of Child \& Adolescent Psychiatry, 52, 547-548. doi:10.1016/j. jaac.2013.03.005

Spagnola, M., \& Fiese, B. H. (2007). Family routines and rituals: A context for development in the lives of young children. Infants \& Young Children, 20, 284-299. doi:10.1097/01. IYC.0000290352.32170.5a

Tripp, G., Schaughency, E. A., Langlands, R., \& Mouat, K. (2007). Family interactions in children with and without ADHD. Journal of Child and Family Studies, 16, 385-400. doi:10.1007/s10826-006-9093-2

Valiente, C., Lemery-Chalfant, K., \& Reiser, M. (2007). Pathways to problem behaviors: Chaotic homes, parent and child effortful control, and parenting. Social Development, 16, 249-267. doi:10.1111/j.1467-9507.2007.00383.x

Vaughn, C., \& Leff, J. (1976). The measurement of expressed emotion in the families of psychiatric patients. British Journal of Social and Clinical Psychology, 15, 157-165. doi:10.1111/j.2044-8260.1976.tb00021.x

Wachs, T. D., \& Evans, G. W. (2010). Chaos in context. In G. W. Evans \& T. D. Wachs (Eds.), Chaos and its influence on children's development (pp. 3-14). Washington DC: American Psychological Association. doi:10.1037/12057-001

Yelland, I., \& Daley, D. (2009). Expressed emotion in children: Associations with sibling relationships. Child: Care, Health and Development, 35, 568-577. doi:10.1111/j.13652214.2009.00958.x

Zaslow, M. J., Weinfield, N. S., Gallagher, M., Hair, E. C., Ogawa, J. R., Egeland, B., . . De Temple, J. M. (2006). Longitudinal 
prediction of child outcomes from differing measures of parenting in a low-income sample. Developmental Psychology, 42, 27-37. doi:10.1037/0012-1649.42.1.27

\section{Author Biographies}

Andrea Wirth, $\mathrm{PhD}$, is a postdoctoral research associate in the Department of Psychology at the Goethe University, Frankfurt, and associated researcher at the Center for Individual Development and Adaptive Education of Children at Risk (IDeA), Frankfurt. Currently, her main areas of interest are psychosocial and familial influences on ADHD and self-regulation.

Tilman Reinelt, $\mathrm{PhD}$, is a postdoctoral research associate at the University of Bremen and associated researcher at the Center for Individual Development and Adaptive Education of Children at Risk (IDeA), Frankfurt. Currently, his main areas of interest are (a) ADHD in children and adolescents, (b) experimental and applied research on self-regulation and executive functions, (c) differential susceptibility models, and (d) resilience in adolescent refugees.

Caterina Gawrilow, $\mathrm{PhD}$, is a professor of school psychology at the Eberhard Karls University in Tübingen and associated researcher at the Deutsche Institut für Internationale Pädagogische
Forschung (DIPF; German Institute for International Educational Research), Frankfurt. Currently, her main areas of interest are ADHD in children and adolescents, experimental and applied research on self-regulation and executive functioning, and intense longitudinal studies.

Christina Schwenck, $\mathrm{PhD}$, is a professor of clinical child and adolescent psychology at the University of Kiel. Currently, her main areas of interest are (a) ADHD in children and adolescents, (b) social cognition in conduct disorder and autism spectrum disorder, (c) selective mutism, and (d) children of mentally ill parents.

Christine M. Freitag, MD, MA, is the director of the Department of Child and Adolescent Psychiatry, Psychosomatics and Psychotherapy, Goethe University, Frankfurt, and chair and professor of Child and Adolescent Psychiatry and Psychotherapy. Her main research areas are genetics, $\mathrm{G} \times \mathrm{E}$ interaction, psychopathology, neuroendocrinology, and therapy of ADHD, Conduct Disorder, and Autism Spectrum Disorders.

Wolfgang A. Rauch, $\mathrm{PhD}$, is a junior research group leader in the Department of Psychology at the Heidelberg University. His research interests include self-regulation, cognitive development, and the associations between the family environment and symptoms of ADHD. 